\title{
Clofarabine, high-dose cytarabine and liposomal daunorubicin in pediatric relapsed/refractory acute myeloid leukemia: a phase IB study
}

\author{
Natasha K.A. van Eijkelenburg, ${ }^{1,2,3^{*}}$ Mareike Rasche, ${ }^{4 *}$ Essam Ghazaly, ${ }^{5}$ \\ Michael N. Dworzak, ${ }^{6}$ Thomas Klingebiel, ${ }^{7}$ Claudia Rossig, ${ }^{8}$ Guy Leverger, ${ }^{9}$ \\ Jan Stary, ${ }^{10}$ Eveline S.J.M. De Bont, ${ }^{11}$ Dana A. Chitu, ${ }^{12}$ Yves Bertrand, ${ }^{13}$ \\ Benoit Brethon, ${ }^{14}$ Brigitte Strahm, ${ }^{15}$ Inge M. van der Sluis, ${ }^{1,3}$ \\ Gertjan J.L. Kaspers, ${ }^{2,16,17}$ Dirk Reinhardt ${ }^{3,17}$ and C. Michel Zwaan ${ }^{1,2,3}$
}

Volume 103(9):1484-1492

\section{Correspondence: \\ c.m.zwaan@erasmusmc.nl \\ Received: December 24, 2017. \\ Accepted: May 16, 2018. \\ Pre-published: May 17, 2018.}

doi:10.3324/haematol.2017.187153

Check the online version for the most updated information on this article, online supplements, and information on authorship \& disclosures: www. haematologica.org/content/103/9/1484

\section{(C)2018 Ferrata Storti Foundation}

Material published in Haematologica is covered by copyright. All rights are reserved to the Ferrata Storti Foundation. Use of published material is allowed under the following terms and conditions:

https://creativecommons.org/licenses/by-nc/4.0/legalcode. Copies of published material are allowed for personal or internal use. Sharing published material for non-commercial purposes is subject to the following conditions:

https://creativecommons.org/licenses/by-nc/4.0/legalcode, sect. 3. Reproducing and sharing published material for commercial purposes is not allowed without permission in writing from the publisher.
${ }^{1}$ Department of Pediatric Oncology/Hematology, Erasmus MC-Sophia Children's Hospital, Rotterdam, the Netherlands; ${ }^{2}$ Department of Pediatric Oncology, Princess Máxima Center for Pediatric Oncology, Utrecht, the Netherlands; ${ }^{3}$ European Consortium for Innovative Therapies for Children with Cancer (ITCC), Villejuif, France; ${ }^{4}$ Department of Pediatric Oncology, University Children's Hospital, Essen, Germany; ${ }^{5}$ Centre for Haemato-Oncology, Barts Cancer Institute, Queen Mary University of London, UK; ${ }^{6}$ Children's Cancer Research Institute and St. Anna Children's Hospital, Department of Pediatrics, Medical University of Vienna, Austria; ${ }^{7}$ Pediatric Hematology/Oncology, Johann Wolfgang Goethe University, Frankfurt, Germany; ${ }^{8}$ Pediatric Hematology and Oncology, University Children's Hospital, Münster, Germany; 'Department of Pediatric Hematology and Oncology, AP-HP, GH HUEP, Trousseau Hospital, Paris, France; ${ }^{10}$ Department of Pediatric Hematology and Oncology, $2^{\text {nd }}$ Faculty of Medicine, Charles University Prague, University Hospital Motol, Czech Republic; ${ }^{11}$ Department of Pediatric Oncology, University Medical Center Groningen, University of Groningen, the Netherlands; ${ }^{12} \mathrm{Clinical}$ Trial Center, Department of Hematology, Erasmus Medical Center, Rotterdam, the Netherlands; ${ }^{13}$ Pediatric Hematology Department, IHOP and Claude Bernard University, Lyon, France; ${ }^{14}$ Department of Pediatric Hematology, Robert Debré Hospital, Paris, France; ${ }^{15}$ Division of Pediatric Hematology and Oncology, Department of Pediatrics and Adolescent Medicine, University of Freiburg, Germany; ${ }^{16}$ Department of Pediatric Oncology, VU University Medical Center, Amsterdam, the Netherlands and ${ }^{17}$ I-BFM-AML committee, Kiel, Germany

*NKAE and MR contributed equally to this work as first authors.

\section{ABSTRACT}

Curvival in children with relapsed/refractory acute myeloid leukemia is unsatisfactory. Treatment consists of one course of flu$\checkmark$ darabine, cytarabine and liposomal daunorubicin, followed by fludarabine and cytarabine and stem-cell transplantation. Study ITCC 020/I-BFM 2009-02 aimed to identify the recommended phase II dose of clofarabine replacing fludarabine in the abovementioned combination regimen (3+3 design). Escalating dose levels of clofarabine (20-40 $\mathrm{mg} / \mathrm{m}^{2} /$ day x 5 days) and liposomal daunorubicin $\left(40-80 \mathrm{mg} / \mathrm{m}^{2} /\right.$ day) were administered with cytarabine $\left(2 \mathrm{~g} / \mathrm{m}^{2} /\right.$ day x 5 days). Liposomal DNR was given on day 1,3 and 5 only. The cohort at the recommended phase II dose was expanded to make a preliminary assessment of anti-leukemic activity. Thirty-four children were enrolled: refractory $1^{\text {st }}$ $(n=11)$, early $1^{\text {st }}(n=15), \geq 2^{\text {nd }}$ relapse $(n=8)$. Dose level $3\left(30 \mathrm{mg} / \mathrm{m}^{2}\right.$ clofarabine; $60 \mathrm{mg} / \mathrm{m}^{2}$ liposomal daunorubicin) appeared to be safe only in patients without subclinical fungal infections. Infectious complications were dose-limiting. The recommended phase II dose was $40 \mathrm{mg} / \mathrm{m}^{2}$ clofarabine with $60 \mathrm{mg} / \mathrm{m}^{2}$ liposomal daunorubicin. Side-effects mainly consisted of infections. The overall response rate was $68 \%$ in 31 response evaluable patients, and $80 \%$ at the recommended phase II dose $(n=10) ; 22$ patients proceeded to stem cell transplantation. The 2year probability of event-free survival (pEFS) was 26.5 \pm 7.6 and probability of survival (pOS) $32.4 \pm 8.0 \%$. In the 21 responding patients, the 2 -year pEFS was $42.9 \pm 10.8$ and pOS $47.6 \pm 10.9 \%$. Clofarabine expo- 
sure in plasma was not significantly different from that in single-agent studies. In conclusion, clofarabine was well tolerated and showed high response rates in relapsed/refractory pediatric acute myeloid leukemia. Patients with (sub)clinical fungal infections should be treated with caution. Clofarabine has been taken forward in the Berlin-Frankfurt-Münster study for newly diagnosed acute myeloid leukemia. The Study ITCC-020 was registered as EUDRA-CT 2009-009457-13; Dutch Trial Registry number 1880.

\section{Introduction}

Despite enhanced cure rates for pediatric acute myeloid leukemia (AML), relapsed patients still suffer from poor clinical outcome, ${ }^{1}$ especially those who relapse within one year of diagnosis. ${ }^{2}$ Recently, a randomized phase III study in relapsed/refractory AML revealed an improved early treatment response when liposomal daunorubicin (DNX) was added to the FLAG (fludarabine, cytarabine and granulocyte-colony stimulating factor (G-CSF)) regimen. ${ }^{2}$ Although this did not translate into a survival benefit [4year probability of survival (pOS) of $38 \pm 3 \%$ ], in Europe, the combination of FLAG and DNX (FLAG-DNX) followed by stem cell transplantation (SCT) was considered the standard treatment for children with AML in first relapse., ${ }^{2,3}$ For several reasons, including data obtained in adults, subsequently G-CSF priming was deleted from the FLAG regimen ${ }^{4,5}$ and the current standard is FLA-DNX. Intensified relapse therapy increased survival over time, ${ }^{6}$ but insufficient cure rates in the $70 \%$ range $(\mathrm{pOS}),{ }^{3}$ and potential long-term toxicities such as anthracycline cardiomyopathy when cumulative dosages exceed 300-400 $\mathrm{mg} / \mathrm{m}^{27,8}$ mean that novel chemotherapy combinations must be developed.

Clofarabine, a structural hybrid of fludarabine and cladribine, was developed to enhance efficacy and stability of the drug, while reducing the formation of toxic compounds like 2-F adenine compared to previous nucleoside analogs. ${ }^{9,10}$ Inhibition of DNA polymerase and ribonucleotide reductase as well as induction of apoptosis, ${ }^{10}$ and enhanced accumulation of cytarabine may contribute to the drug's high antitumor activity. ${ }^{11}$

The first pediatric phase I study of clofarabine identified a maximum tolerated dose (MTD) of $52 \mathrm{mg} / \mathrm{m}^{2} /$ day, with reversible hepatotoxicity and skin rash as dose-limiting toxicities. ${ }^{12}$ Based on a phase II study, clofarabine was approved in 2004 for relapsed pediatric ALL. ${ }^{13}$ However, in relapsed pediatric AML, activity of clofarabine was not confirmed, with a response rate of only $26 \%$, mainly consisting of partial responses, probably due to the inclusion of heavily pre-treated patients. ${ }^{13}$ In contrast, in adult AML, clofarabine showed antileukemic activity in several early phase studies. ${ }^{14.16}$ Randomized data showed that, even though remission rates were improved in untreated older patients with AML and high-risk myelodysplastic syndrome (MDS), no survival benefit of clofarabine (20 $\mathrm{mg} / \mathrm{m}^{2} / \mathrm{d}$ for 5 days) over low-dose cytarabine was shown. ${ }^{17}$ Moreover, another randomized study comparing cytarabine with clofarabine $\left(20 \mathrm{mg} / \mathrm{m}^{2} / \mathrm{d}\right.$ for 5 days $)$ in induction courses I and II in elderly AML also failed to show a survival benefit. ${ }^{18}$ However, a recent study by the HOVON-group did show a survival advantage for patients randomized to clofarabine in intermediate-risk AML subsets, albeit at a very low dose of $10 \mathrm{mg} / \mathrm{m}^{2} / \mathrm{d}$ for five days added to induction courses I and II. ${ }^{19}$
In pediatric ALL, clofarabine combination therapy was developed to overcome resistance, e.g. combinations with cyclophosphamide, or etoposide and cyclophosphamide, or topotecan, vinorelbine and thiopeta. ${ }^{20-23}$ In children with relapsed/refractory AML, clofarabine (52 $\mathrm{mg} / \mathrm{m}^{2} / \mathrm{d}$ for 5 days) with cytarabine $\left(1 \mathrm{~g} / \mathrm{m}^{2} / \mathrm{d}\right.$ for 5 days $)$ resulted in a 3 -year pOS of $46 \% \pm 27 \%$ in responders. ${ }^{24}$ In the CLOUD study, 9 children with relapsed/refractory AML were treated with clofarabine $\left(30 \mathrm{mg} / \mathrm{m}^{2} / \mathrm{d}\right.$ for 5 days) and liposomal daunorubicin $\left(60 \mathrm{mg} / \mathrm{m}^{2}\right.$, days 1,3 and 5); 33\% obtained complete remission (CR) and were subsequently transplanted. ${ }^{25}$

In this study, we aimed to combine clofarabine with high-dose cytarabine and liposomal daunorubicin as in the FLA-DNX regimen, replacing fludarabine with clofarabine assuming that this may have greater anti-leukemic potential when tolerable. The treatment schedule was based on an adapted 'Faderl regimen' developed in adult AML. ${ }^{26,27}$

\section{Methods}

Study ITCC-020 (EUDRA-CT 2009-009457-13; Dutch Trial Registry number 1880) was an investigator-initiated open-label phase IB dose-escalation study sponsored by Erasmus MC, Rotterdam, the Netherlands. Patients were enrolled in 15 centers in 5 countries within the Innovative Therapies for Children with Cancer (ITCC) consortium.

\section{Study design}

The primary objective was to establish the MTD and recommended phase II dose (RP2D) of clofarabine in combination with cytarabine and DNX in relapsed/refractory pediatric AML. Doselimiting toxicities were evaluated in the first course only. Secondary objectives included tabulation of additional safety and tolerability data across both treatment courses, preliminary estimation of response, event-free survival (EFS), and overall survival $(\mathrm{OS})$, and the pharmacokinetics (PK) of clofarabine in this combination [serum and cerebrospinal fluid (CSF)]. A classical 3+3 design was used with dose escalation to MTD, after which the cohort was expanded $(n=10)$ at the RP2D. Separate expansion cohorts were planned for dose level (DL) 1-4 and for DL5 (in early 1 first relapse only), respectively, when considered safe.

\section{Patient eligibility}

Pediatric patients below 19 years of age with early $1^{\text {st }}$ relapse (within 12 months from initial diagnosis), refractory $1^{\text {st }}$ relapse ( $\geq$ $20 \%$ blasts in the bone marrow after the first course of standard re-induction therapy), or those with at least a second relapsed AML were eligible. Only patients with early $1^{\text {st }}$ relapse without prior SCT were eligible for DL5. Inclusion and exclusion criteria are described in Online Supplementary Methods S1, and included recovery from prior organ toxicity. An amendment in November 2011 excluded patients with evidence for subclinical fungal infections using high-resolution computed tomography (CT) scan of 
the thorax, and elevated serum levels of galactomannan.

All patients/parents had to provide written informed consent according to local law and regulations, after the institutional review boards of the participating institutes approved the study. The study was conducted in accordance with good clinical practice guidelines and the Declaration of Helsinki.

\section{Treatment}

Clofarabine and DNX dosages were escalated from 20-40 $\mathrm{mg} / \mathrm{m}^{2} /$ day at days $1-5$, and $40-80 \mathrm{mg} / \mathrm{m}^{2} /$ day at days 1,3 and 5 , respectively, whereas the dose of cytarabine was fixed at $2 \mathrm{~g} / \mathrm{m}^{2} / \mathrm{d}$ for days 1-5 (Table 1, detailed information in Online Supplementary Methods S2). DL5 (DNX $80 \mathrm{mg} / \mathrm{m}^{2} /$ day at days 1, 3 and 5) was considered as a separate cohort with restricted inclusion criteria. This cohort was added as up-front pediatric AML protocols use DNX at this dose level rather than $60 \mathrm{mg} / \mathrm{m}^{2} / \mathrm{d} 28$ (Figure 1).

\section{Safety and efficacy evaluations}

Adverse events (AEs) were graded according to the Common Terminology Criteria for Adverse Events v.3.0. Dose Limiting Toxicities (DLT) were defined as grade 3 or 4 non-hematologic AEs and hematologic AEs lasting longer than 42 days, limited to the first course, and at least possibly drug-related, with some exceptions (definitions and efficacy evaluation in Online Supplementary Methods S3 and Table S1).

\section{Statistical analysis}

Dosing and efficacy were analyzed using descriptive statistics. Survival estimates were computed by Kaplan-Meier. The database lock for this analysis was set at $11^{\text {th }}$ February 2018. All analyses were performed with Stata v.13.1.

Further information concerning pharmacokinetics and statistical analysis is available in Online Supplementary Methods S4, Methods S5 and Table S2.

Table 1. Dose levels of clofarabine, liposomal daunorubicin and cytarabine.

\begin{tabular}{|c|c|c|c|}
\hline $\begin{array}{l}\text { Age } \geq 1 \text { year } \\
\text { (Age < } 1 \text { year) }\end{array}$ & Clofarabine & DNX & Ara-C \\
\hline Dose level -1 & $\begin{array}{c}15 \mathrm{mg} / \mathrm{m}^{2} / \mathrm{d} \times 5 \mathrm{~d} \\
(0.5 \mathrm{mg} / \mathrm{kg} / \mathrm{d} \text { x } 5 \mathrm{~d})\end{array}$ & $\begin{array}{l}40 \mathrm{mg} / \mathrm{m}^{2} / \text { day } 1-3-5 \\
(1.3 \mathrm{mg} / \mathrm{kg} / \mathrm{d} 1-3-5)\end{array}$ & $\begin{array}{c}2 \mathrm{gr} / \mathrm{m}^{2} / \mathrm{d} \times 5 \mathrm{~d} \\
(70 \mathrm{mg} / \mathrm{kg} / \mathrm{d} \times 5 \mathrm{~d})\end{array}$ \\
\hline Dose level 1 (starting dose) & $\begin{array}{c}20 \mathrm{mg} / \mathrm{m}^{2} / \mathrm{d} \times 5 \mathrm{~d} \\
(0.7 \mathrm{mg} / \mathrm{kg} / \mathrm{d} \times 5 \mathrm{~d})\end{array}$ & $\begin{array}{c}40 \mathrm{mg} / \mathrm{m}^{2} / \mathrm{d} 1-3-5 \\
(1.3 \mathrm{mg} / \mathrm{kg} / \mathrm{d} 1-3-5)\end{array}$ & $\begin{array}{c}2 \mathrm{gr} / \mathrm{m}^{2} / \mathrm{d} \times 5 \mathrm{~d} \\
(70 \mathrm{mg} / \mathrm{kg} / \mathrm{d} \times 5 \mathrm{~d})\end{array}$ \\
\hline Dose level 2 & $\begin{array}{c}30 \mathrm{mg} / \mathrm{m}^{2} / \mathrm{d} \text { x } 5 \mathrm{~d} \\
(1.0 \mathrm{mg} / \mathrm{kg} / \mathrm{d} \times 5 \mathrm{~d})\end{array}$ & $\begin{array}{c}40 \mathrm{mg} / \mathrm{m}^{2} / \mathrm{d} 1-3-5 \\
(1.3 \mathrm{mg} / \mathrm{kg} / \mathrm{d} 1-3-5)\end{array}$ & $\begin{array}{c}2 \mathrm{gr} / \mathrm{m}^{2} / \mathrm{d} \times 5 \mathrm{~d} \\
(70 \mathrm{mg} / \mathrm{kg} / \mathrm{d} \times 5 \mathrm{~d})\end{array}$ \\
\hline Dose level 3A & $\begin{array}{c}30 \mathrm{mg} / \mathrm{m}^{2} / \mathrm{d} \times 5 \mathrm{~d} \\
(1.0 \mathrm{mg} / \mathrm{kg} / \mathrm{d} \times 5 \mathrm{~d})\end{array}$ & $\begin{array}{c}60 \mathrm{mg} / \mathrm{m}^{2} / \mathrm{d} 1-3-5 \\
(2.0 \mathrm{mg} / \mathrm{kg} / \mathrm{d} 1-3-5)\end{array}$ & $\begin{array}{c}2 \mathrm{gr} / \mathrm{m}^{2} / \mathrm{d} \times 5 \mathrm{~d} \\
(70 \mathrm{mg} / \mathrm{kg} / \mathrm{d} \text { x } 5 \mathrm{~d})\end{array}$ \\
\hline Dose level 3B* & $\begin{array}{c}30 \mathrm{mg} / \mathrm{m}^{2} / \mathrm{d} \text { x } 5 \mathrm{~d} \\
(1.0 \mathrm{mg} / \mathrm{kg} / \mathrm{d} \text { x } 5 \mathrm{~d})\end{array}$ & $\begin{array}{c}60 \mathrm{mg} / \mathrm{m}^{2} / \mathrm{d} 1-3-5 \\
(2.0 \mathrm{mg} / \mathrm{kg} / \mathrm{d} 1-3-5)\end{array}$ & $\begin{array}{c}2 \mathrm{gr} / \mathrm{m}^{2} / \mathrm{d} \times 5 \mathrm{~d} \\
(70 \mathrm{mg} / \mathrm{kg} / \mathrm{d} \times 5 \mathrm{~d})\end{array}$ \\
\hline Dose level 4 & $\begin{array}{c}40 \mathrm{mg} / \mathrm{m}^{2} / \text { day x } 5 \mathrm{~d} \\
(1.3 \mathrm{mg} / \mathrm{kg} / \text { day x } 5 \mathrm{~d})\end{array}$ & $\begin{array}{c}60 \mathrm{mg} / \mathrm{m}^{2} / \mathrm{d} 1-3-5 \\
(2.0 \mathrm{mg} / \mathrm{kg} / \mathrm{d} 1-3-5)\end{array}$ & $\begin{array}{c}2 \mathrm{gr} / \mathrm{m}^{2} / \mathrm{d} \times 5 \mathrm{~d} \\
(70 \mathrm{mg} / \mathrm{kg} / \mathrm{d} \times 5 \mathrm{~d})\end{array}$ \\
\hline Dose level $5^{* *}$ & $40 \mathrm{mg} / \mathrm{m}^{2} / \mathrm{day} \times 5 \mathrm{~d}$ & $80 \mathrm{mg} / \mathrm{m}^{2} / \mathrm{d} 1-3-5$ & $2 \mathrm{gr} / \mathrm{m}^{2} / \mathrm{d} \times 5 \mathrm{~d}$ \\
\hline
\end{tabular}

Ara-C: cytarabine; DNX:liposomal daunorubicin. *Dose level 3B: cohort 3 was repeated after an amendment implementing screening for subclinical fungal infections. * Dose level 5: this cohort was open for patients with early $1^{\text {st }}$ relapse of acute myeloid leukemia without prior stem cell transplantation only. Dosages in brackets are for children below 1 year of age or below $10 \mathrm{~kg}$ body weight.

Clofarabine/Cytarabine/DNX

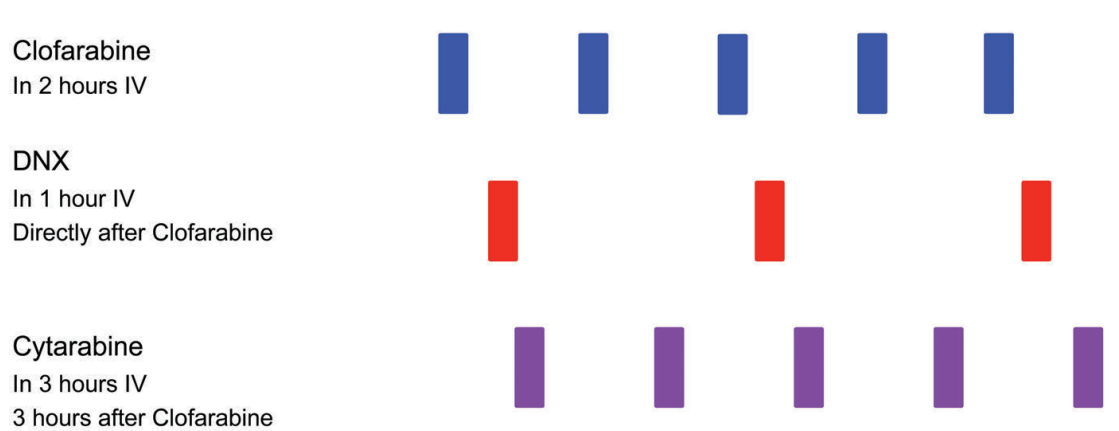

3 hours after Clofarabine
Figure 1. Treatment schedule. Clofarabine was administered intravenously (IV) in 2 hours $(h)$ (days 1-5); liposomal daunorubicin (DNX) in $1 \mathrm{~h}$ (days 1, 3, 5); DNX in $1 \mathrm{~h}$ (days $1,3,5$ ), starting 30 minutes after the end of clofarabine; cytarabine was administered (IV) in $3 \mathrm{~h}$ (days 1-5), starting $3 \mathrm{~h}$ after the end of clofarabine. Intrathecal therapy was administered at day 6 with cytarabine for prophylaxis, or triple therapy (cytarabine and methotrexate and prednisolone) with age-adjusted dosages in case of central nervous system involvement. G-CSF: granulocyte-colony stimulating factor.

$\begin{array}{llllll} & & & \\ & & & & \\ \text { Day 1 } & 2 & 3 & 4 & 5 & 6 \\ & & & & & \text { intrathecal } \\ & & & & & \text { No G-CSF priming }\end{array}$




\section{Results}

\section{Patients and treatment}

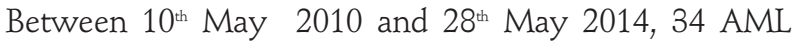
patients (early first relapse, $\mathrm{n}=15$; refractory first relapse, $\mathrm{n}=11 ; \geq 2^{\text {nd }}$ relapse, $\mathrm{n}=8$ ) were recruited. The median age was 8.3 years (range 1.0-19.6 years); the median WBC $4.6 \times 10^{9} / \mathrm{L}$ (range $0.3-326 \times 10^{9} / \mathrm{L}$ ), and $41 \%$ of patients were female. We had conclusive cyto(genetic) data from initial diagnosis in 30 of 34 patients, and from time point of inclusion in this study in 23 patients. None of these karyotypes included good risk characteristics such as $\mathrm{t}(8 ; 21)(\mathrm{q} 22 ; \mathrm{q} 22)$ or inv(16)(p13q22)/t(16;16)(p13;q22). Eighteen patients had been pre-treated with FLAG-DNX reinduction according to protocol AML-BFM 2001/01.2 Twelve patients had received a prior SCT (4 in CR1; 7 in CR2; and 1 unknown), including one patient with 2 prior SCTs. For 32 of 34 patients, prior cumulative dose of anthracycline was calculated using the equivalent formula, as previously described. ${ }^{29}$ With respect to the missing equivalent doses, prior amsacrine and prior liposomal daunorubicin were not included in the calculation. Prior anthracycline dosages are heterogenous in this cohort (range 80-686 mg/m²). Detailed patients' characteristics are provided in Table 2.

A total of 46 CLARA-DNX cycles were administered: 12 patients received two cycles (1 in DL3A; 2 in DL3B; 6 in DL4; 3 in DL5). In 31 patients, cycle 1 was given according to the schedule provided in the protocol. Deviations concerned intrathecal treatment (delayed or deleted in one patient each), and in one patient cytarabine was halted at day 3 due to an allergic reaction. The median absolute dose of clofarabine in cycle one was $160 \mathrm{mg}$ (range $38-380 \mathrm{mg}$ ) $165 \mathrm{mg}$ (range 38-456) for DNX, and $9.37 \mathrm{~g}$ (range 1.26-19 g) for cytarabine.

Table 2. Patients' baseline characteristics.

\begin{tabular}{|c|c|c|c|c|c|c|c|}
\hline Characteristic & $\begin{array}{l}\text { ALL patients } \\
(\mathrm{N}=34) \\
\mathrm{N} . \quad(\%)\end{array}$ & $\begin{array}{c}D L 1 \\
(N=4) \\
N .\end{array}$ & $\begin{array}{c}\text { DL2 } \\
(N=3) \\
N .\end{array}$ & $\begin{array}{c}\text { DL3A } \\
(\mathrm{N}=6) \\
\mathrm{N} .\end{array}$ & $\begin{array}{c}\text { DL3B } \\
(N=6) \\
N .\end{array}$ & $\begin{array}{c}\text { DL4 } \\
(\mathrm{N}=10) \\
\mathrm{N} .\end{array}$ & $\begin{array}{c}\text { DL5 } \\
(\mathrm{N}=5) \\
\mathrm{N} .\end{array}$ \\
\hline \multicolumn{8}{|l|}{ Age, years } \\
\hline Median & 8.3 & 7.1 & 14.2 & 12.9 & 4.6 & 10.2 & 2.4 \\
\hline Range & $1.0-19.6$ & $2.8-8.8$ & $1.3-15.6$ & $1.0-17.6$ & $2.5-19.6$ & $1.4-18.8$ & $1.3-16.0$ \\
\hline \multicolumn{8}{|l|}{ Sex } \\
\hline Male & $20(58.8)$ & 3 & 3 & 2 & 4 & 6 & 2 \\
\hline Female & $14(41.2)$ & 1 & - & 4 & 2 & 4 & 3 \\
\hline \multicolumn{8}{|c|}{ FAB at initial diagnosis } \\
\hline M0 & 4 & 1 & 1 & - & - & 2 & - \\
\hline M1 & 3 & - & - & 1 & - & - & 2 \\
\hline M2 & 6 & - & 1 & - & 2 & 2 & 1 \\
\hline M4 & 4 & 1 & - & 2 & - & 1 & - \\
\hline M5 & 14 & 1 & - & 3 & 3 & 5 & 2 \\
\hline M6 & 1 & - & 1 & - & - & - & - \\
\hline Non-classified & 2 & 1 & - & - & 1 & - & - \\
\hline \multicolumn{8}{|l|}{ Disease status } \\
\hline Early $1^{\text {st }}$ rel & 15 & - & 1 & - & 3 & 6 & 5 \\
\hline Refractory $1^{\text {st }}$ rel & 11 & 2 & 1 & 4 & 2 & 2 & - \\
\hline$\geq 2^{\text {nd }} \mathrm{rel}$ & 8 & 2 & 1 & 2 & 1 & 2 & - \\
\hline \multicolumn{8}{|c|}{ WBC at inclusion $\left(x 10^{\circ} / \mathrm{L}\right)$} \\
\hline Median & 4.6 & 3 & 6 & 3 & 4 & 3 & 4 \\
\hline Range & $0.3-326$ & $1-5$ & $1-127$ & $1-326$ & $0-34$ & $0-30$ & $1-6$ \\
\hline$<10$ & 27 & 4 & 2 & 4 & 4 & 6 & 5 \\
\hline$\geq 10$ & 6 & - & 1 & 2 & 2 & 2 & - \\
\hline \multicolumn{8}{|l|}{ Prior SCT } \\
\hline NO SCT & 22 & 2 & 1 & 4 & 2 & 8 & 5 \\
\hline $\mathrm{SCT}$ in $1^{\text {st }} \mathrm{CR}$ & 4 & - & 1 & 1 & 2 & - & - \\
\hline $\mathrm{SCT}$ in $2^{\text {nd }} \mathrm{CR}$ & 7 & 2 & 1 & 1 & 1 & 2 & - \\
\hline Unknown & 1 & - & - & - & 1 & - & - \\
\hline \multicolumn{8}{|c|}{ Pre-treatment with FLA-DNX } \\
\hline Yes & 18 & 4 & 1 & 6 & 3 & 4 & - \\
\hline No & 16 & - & 2 & - & 3 & 6 & 5 \\
\hline
\end{tabular}

WBC: white blood cells; FAB: French-American-British; SCT: stem cell transplantation; FLA: fludarabine, cytarabine (Ara-C); DNX: liposomal daunorubicin; CR: complete remission; DL: dose-level; N: number of patients; rel: relapse. 


\section{Safety and tolerability}

Initial dose-escalation was halted at DL3 because of DLTs (3 Grade 3 pulmonary fungal infections (aspergillosis); 1 Grade 3 non-fungal pulmonary infection). An amendment was issued to repeat cohort 3 after adding screening for subclinical fungal infections, and only one DLT in 6 patients was noted (Grade 3 pulmonary candida infection), hence escalation to DL4 was pursued. In DL4 only one DLT was noted (Grade 4 septicemia). As DL4 was considered safe, this dose-level was expanded to 10 patients. Subsequently, DL5 was opened for patients with early $1^{\text {st }}$ relapse without prior SCT. At DL5, 2 of 5 patients experienced DLT (1 Grade 3 pseudomonas aeruginosa cellulitis and 1 Grade 3 Gram-negative septicemia), and DL5 was closed therafter (Table 3). Of note, the use of prophylactic antibacterial, antifungals, and antiviral agents was recommended according to each institution's guidelines. Twenty-eight of 34 patients received anti-fungal prophylaxis with azoles (either itraconazole, voriconazole or fluconazole); 17 of 34 patients were on prophylactic treatment with amphotericin B. Hence 11 of 34 patients received both azole prophylaxis as well as amphotericin $B$.

In total, 34 SAEs were reported, mostly consisting of febrile neutropenia $(n=18)$, documented infections $(n=9)$, or gastrointestinal SAEs $(\mathrm{n}=3$ ) (Online Supplementary Table S3). Non-hematologic AEs related to the first cycle of study treatment are summarized in Table 3. Overall, the most common treatment-related AEs were gastrointestinal, pain and infection. These non-hematologic AEs were mild (Grade 1-2) in most patients. In 2 patients, acute renal failure was reported, one in combination with a tumor lysis syndrome. Another patient had a capillary leak syndrome with ascites and reduced diuresis. Hematologic AEs occurred frequently and mostly concerned Grade 3-4 myelosuppression, not resulting in DLTs (data not shown).

Overall, 21 patients died: 2 as the result of an $\mathrm{AE}$ (one multi-organ failure secondary to febrile neutropenia, 1 hypoxia and respiratory and cardiovascular failure); 15 deaths were due to progressive leukemia following other treatment attempts in some but not all patients. The remaining 4 deaths were: SCT procedure related $(n=2)$, lung toxicity after allogeneic transplantation with cytomegalovirus (CMV) reactivation ( $n=1)$, and invasive aspergillosis $(n=1)$.

\section{Efficacy}

Of 31 evaluable patients, the ORR was $68 \%$ after the $1^{\text {st }}$ cycle of treatment, including $5(16 \%)$ patients with CR, 15 (48\%) patients with CR with incomplete blood count recovery (CRi), and 1 patient with a partial response (PR) $(3 \%)$. Overall response rate (ORR) differed according to disease phase: $87 \%$ in 15 patients with early $1^{\text {st }}$ relapse;

Table 3. Non-hematologic adverse events in the first treatment cycle.

\begin{tabular}{|c|c|c|c|c|c|}
\hline \multirow[t]{2}{*}{$\begin{array}{l}\text { AEs } \\
\text { AE term }\end{array}$} & Total & \multicolumn{2}{|c|}{$\begin{array}{l}\text { Grade 1-2 } \\
n(\%)\end{array}$} & \multicolumn{2}{|c|}{$\begin{array}{l}\text { Grade 3-4 } \\
\text { n (\%) }\end{array}$} \\
\hline & $\begin{array}{l}\text { All grades, } \\
\text { n (\%) }\end{array}$ & AES & Patients & AES & Patients \\
\hline Gastrointestinal & $114(24)$ & $96(29)$ & $27(79)$ & $18(13)$ & $14(41)$ \\
\hline Pain & $62(13)$ & $54(17)$ & $16(47)$ & $8(6)$ & $7(21)$ \\
\hline Infection & $61(13)$ & $9(3)$ & $8(24)$ & $52(36)$ & $27(79)$ \\
\hline Metabolic/laboratory & $46(10)$ & $37(11)$ & $8(24)$ & $9(6)$ & $5(15)$ \\
\hline Skin/dermatological & $34(7)$ & $31(9)$ & $24(71)$ & $3(2)$ & $3(9)$ \\
\hline Constitutional symptoms & $2(5)$ & $22(7)$ & $11(32)$ & $2(1)$ & $2(6)$ \\
\hline Pulmonary/upper respiratory & $19(4)$ & $13(4)$ & $9(27)$ & $6(4)$ & $3(9)$ \\
\hline Cardiac problems including arrhythmia & $13(3)$ & $8(2)$ & $7(21)$ & $5(3)$ & $4(12)$ \\
\hline Neurology (or ocular/visual) & $10(7)$ & $14(3)$ & $11(32)$ & $3(2)$ & $3(9)$ \\
\hline Allergy/immunology & $8(2)$ & $7(2)$ & $6(18)$ & $1(<1)$ & $1(3)$ \\
\hline \multicolumn{2}{|c|}{ Others (renal/genitourinary/vascular/syndromes) 5(1) } & - & - & $5(3)$ & $4(12)$ \\
\hline \multicolumn{3}{|c|}{$\begin{array}{l}\text { DLTs } \\
\text { Dose level } \\
\\
\text { per dose level }(n)\end{array}$} & $\begin{array}{l}\text { Patients } \\
\text { with DLT (n) }\end{array}$ & \multicolumn{2}{|c|}{ Details about DLTs } \\
\hline Dose level 1 & \multicolumn{2}{|c|}{4} & 1 & \multicolumn{2}{|c|}{ Gr 3 Streptococcal infection } \\
\hline Dose level 2 & \multicolumn{2}{|c|}{3} & 0 & \multicolumn{2}{|c|}{ None } \\
\hline Dose level 3A & \multicolumn{2}{|c|}{6} & 4 & \multicolumn{2}{|c|}{$\begin{array}{l}\text { Gr } 3 \text { Pulmonary infection including } 3 \\
\text { fungal infections/ aspergillosis }\end{array}$} \\
\hline Dose level 3B & \multicolumn{2}{|c|}{6} & 1 & \multicolumn{2}{|c|}{$\begin{array}{l}\text { Gr } 3 \text { Pulmonary infection: } \\
\text { fungal infection / candida albicans }\end{array}$} \\
\hline Dose level 4 & \multicolumn{2}{|c|}{10} & 1 & \multicolumn{2}{|c|}{ Gr 3 Sepsis } \\
\hline Dose level 5 & \multicolumn{2}{|c|}{5} & 2 & \multicolumn{2}{|c|}{$\begin{array}{c}\text { Gr } 3 \text { Cellulitis infection (pseudomonas) } \\
\text { Gr } 3 \text { Sepsis }\end{array}$} \\
\hline
\end{tabular}


$27 \%$ in 11 patients with refractory $1^{\text {st }}$ relapse; and $50 \%$ in 8 patients with $\geq 2^{\text {nd }}$ relapse (Table 4 ). Of the 18 patients pre-treated with FLA-DNX (refractory $1^{\text {st }}$ relapse, $\mathrm{n}=11$; second relapse $n=7), 6$ patients ( $5 \mathrm{CR} / 1 \mathrm{CRi}$ ) responded $(33 \%)$. Three responders ( $1 \mathrm{CR} / 2 \mathrm{CRi}$ ) were seen in the group of refractory $1^{\text {st }}$ relapse patients. In the expansion cohort at DL4 $(\mathrm{n}=10)$, the overall response rate was $80 \%$ (2 CR, 5 Cri, 1 PR) (Online Supplementary Table S4). In 9 of the 18 patients with FAB M4 and M5 AML an objective response was seen; this was equally divided between both groups (FAB M4 and M5). Of the 13 patients with other FAB classifications, 9 objective responses were seen $(69 \%$, $\mathrm{P}$ M4/M5 vs. other FAB 0.284).

Following clofarabine, 22 patients underwent SCT (17 MUD, 1 matched family donor, 1 HLA identical sibling and 2 haplo-identical, 1 unknown). Of the 21 clofarabine responding patients, 18 subsequently underwent SCT. Overall, 9 of the 22 patients who were transplanted died (6 MUD, 1 matched family donor, 1 haplo-identical, 1 unknown); this included 2 patients with SCT-procedurerelated deaths and one death due to lung toxicity with CMV reactivation. The remaining patients died due to progressive leukemia. At time of database lock, 10 of 34 patients were alive with a median survival time of 56 months (range 32.3-78.4 months). The 1-year pEFS was $35.3 \pm 8.2 \%$ and the pOS $50.0 \pm 8.6 \%$ (Figure $2 \mathrm{~A}$ and $\mathrm{B}$ ); the 2 -year pEFS was $26.5 \pm 7.6 \%$ and the 2 -year pOS $32.4 \pm 8.0 \%$. The 1 -year pEFS was $57.1 \pm 10.8 \%$ in the 21 responding patients, and the pOS was $71.4 \pm 9.9 \%$; the 2 year pEFS was $42.9 \pm 10.8 \%$ and the pOS $47.6 \pm 10.9 \%$ (data not shown). Most events in the 21 responders were due to relapse (Figure $2 \mathrm{C}$ ). In the 10 patients treated at the

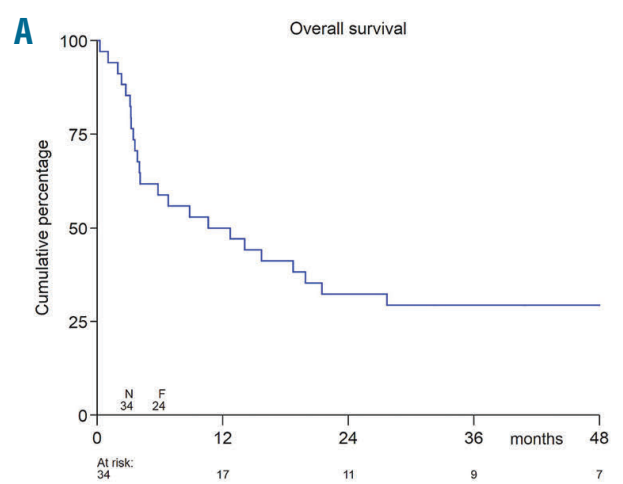

C
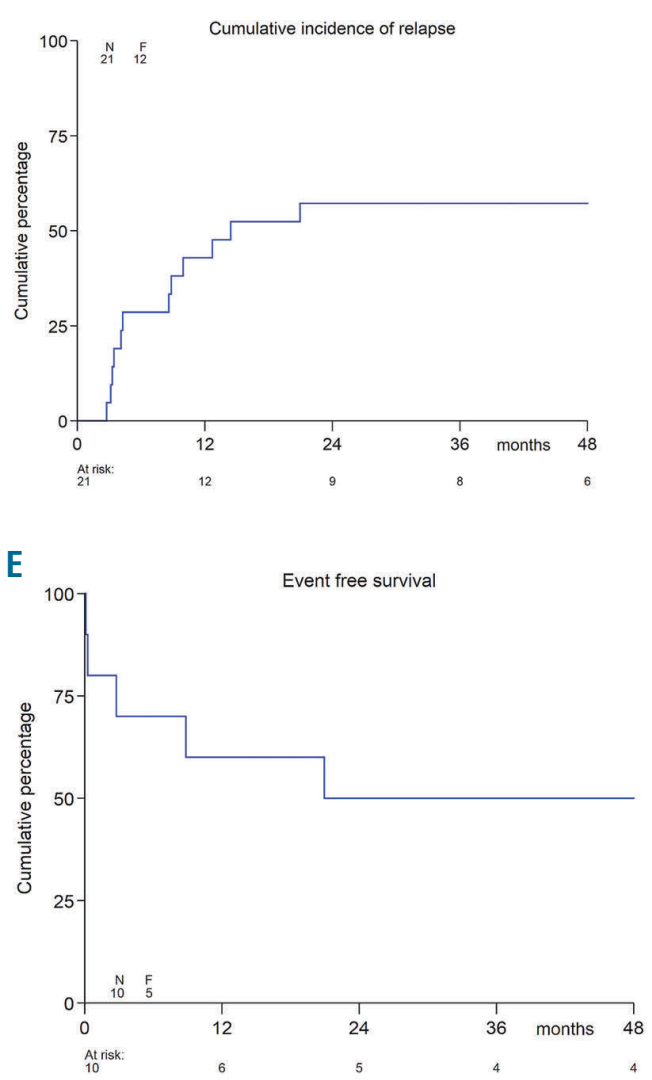
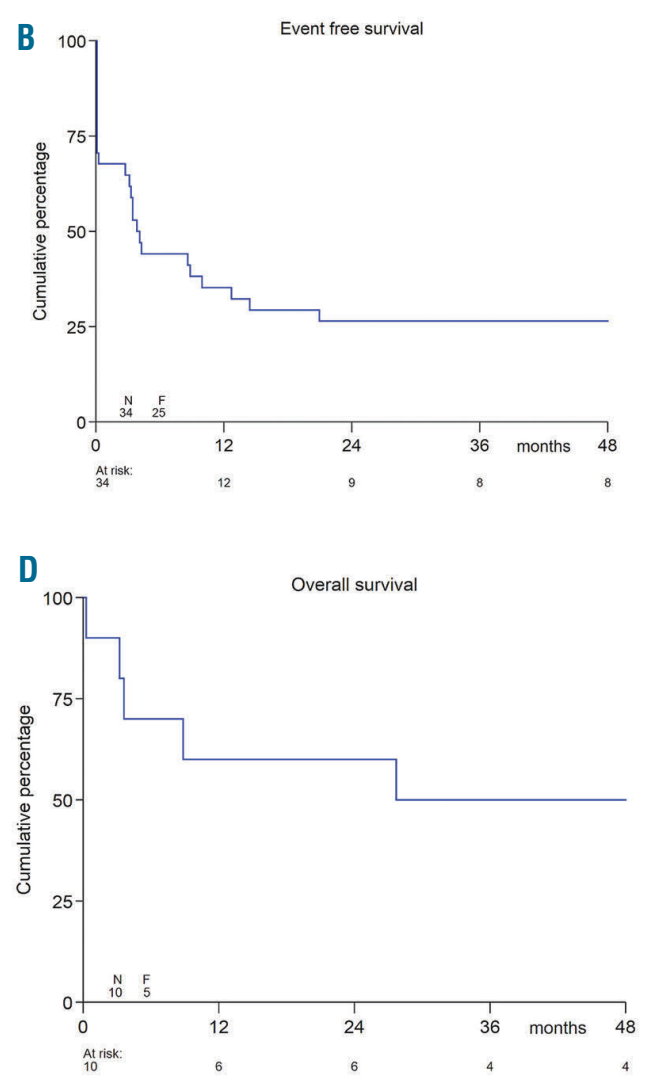

Figure 2. Survival estimates after clofarabine combination chemotherapy reinduc tion. (A) Overall survival of all patients. (B) Event-free survival of all patients. (C) Cumulative Incidence of relapse of the 21 responding patients. (D) Overall survival of all patients at dose level (DL) 4. (E) Event-free survival of all patients at DL4. N: number; F: females; F: failure (event). 
RP2D at DL4, both 1-year pEFS and pOS were $60.0 \pm 15.5 \%$, while 2 -year pEFS was $50.0 \pm 15.8 \%$ and 2 year pOS $60.0 \pm 15.5 \%$ (Figure $2 \mathrm{D}$ and $\mathrm{E}$ ).

\section{Pharmacokinetic analysis}

Blood samples were available from the first 19 patients, after which collection of PK data was halted after interim analysis. Comparison of normalized plasma concentrations at day 5 pre-dose and 24 hours (h) after the last infusion of clofarabine showed similar results with a median concentration of 0.12 and $0.10 \mathrm{ng} / \mathrm{mL} / \mathrm{mg}$, indicating a steady state plasma concentration. The median AUC at day 1 was $28.0 \mathrm{ng} / \mathrm{mL} / \mathrm{mg} / \mathrm{h}$ (range 6.0 to 401.2 ) and 44.0 $\mathrm{ng} / \mathrm{mL} / \mathrm{mg} / \mathrm{h}$ (range 19.4 to 135.9 ) at day 5 . Clofarabine t1/2 was identical at day 1 and day 5 (average value of 1.5 h) (Online Supplementary Figure S3A).

Clofarabine levels in CSF $(n=11)$ ranged from $0.3 \mathrm{ng} / \mathrm{mL}$ to $3.2 \mathrm{ng} / \mathrm{mL}$ [median CSF penetration (CSF conc/plasma conc) was $32.9 \%$ (range $8.0-66.5 \%$ )]. These data are in contrast with the previously reported low clofarabine median penetration of $5 \%$ (range $3-26 \%$ ) into the CSF in non-human primates. ${ }^{30}$

Bonate et al. ${ }^{31}$ have fit clofarabine single-agent PK data derived from 3 clinical trials (i.e. the ID99-383 study recruiting pediatric hematologic malignancies, the CLO212 study in pediatric ALL, and the CLO-222 study in pediatric refractory AML) using a non-parametric LOESS fit to the observed dose normalized concentration-time plot. Our clofarabine PK data fitted well with the Bonate et al. 2004 PK model (Figure 3B), confirming that the current combination did not alter clofarabine PK. Furthermore, our PK data in combination were not significantly different from our data with single-agent clofarabine in relapsed ALL patients, ${ }^{32}$ suggesting that clofarabine has no major drug-drug interaction with either cytarabine or daunorubicin which can affect clofarabine PK.

\section{Discussion}

In this phase IB study, the RP2D of clofarabine in combination with cytarabine and DNX was established at 40 $\mathrm{mg} / \mathrm{m}^{2} /$ day for five consecutive days in combination with $60 \mathrm{mg} / \mathrm{m}^{2}$ DNX at days 1,3 and 5 and cytarabine 2 $\mathrm{gram} / \mathrm{m}^{2}$ for five days in patients with no clinical evidence of subclinical fungal infections at time of treatment. This regimen resulted in a high ORR of $68 \%$ in 31 response evaluable patients, and $80 \%$ at the RP2D $(n=10)$.

In general, the combination of clofarabine, liposomal
A

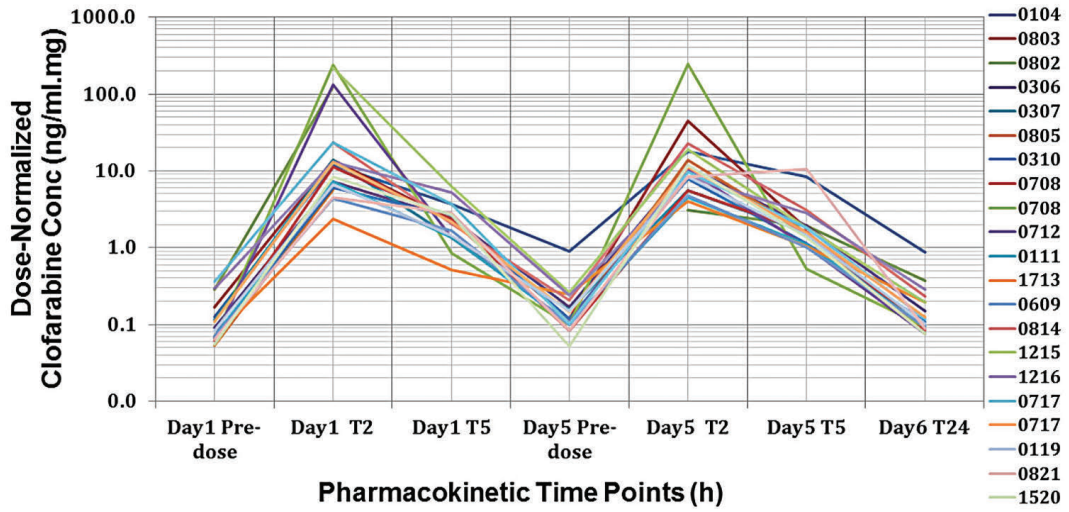

B

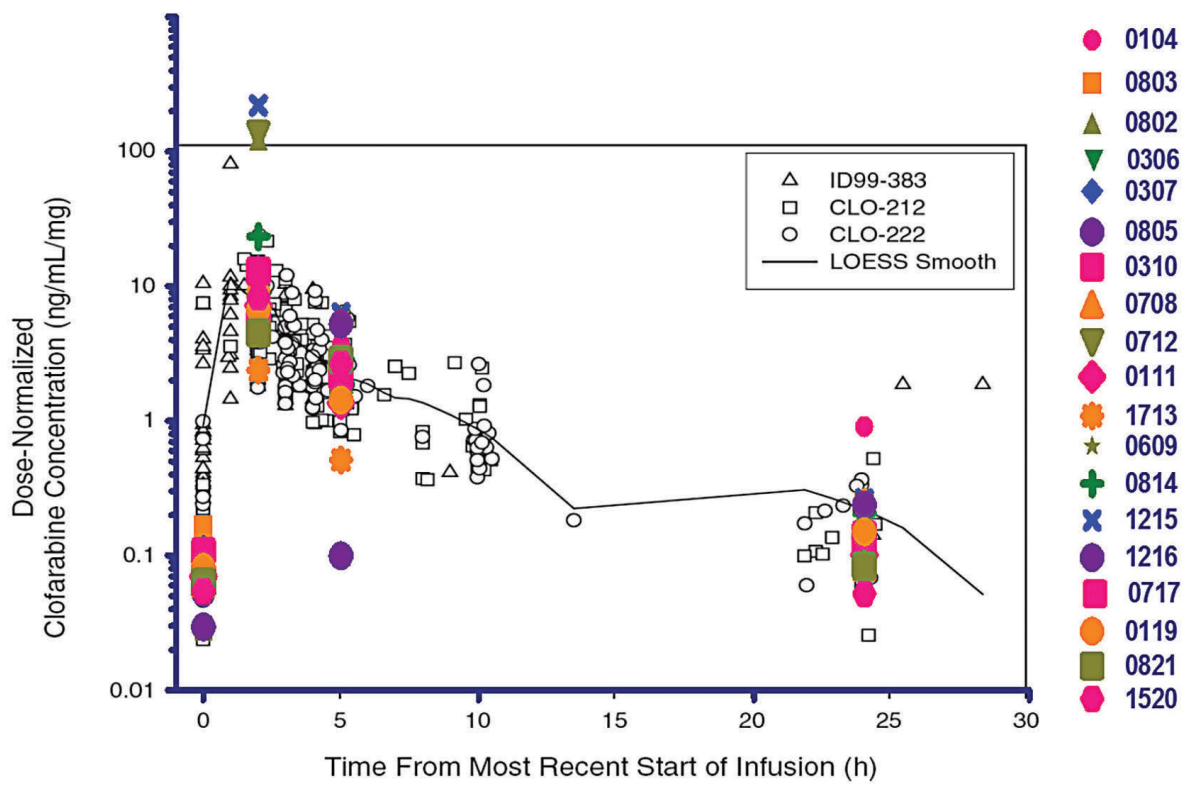

Figure 3. Clofarabine pharmacokinetics and Ppasma concentrations.

Clofarabine plasma concentrations normalized to infused dose $(\mathrm{ng} / \mathrm{mL} / \mathrm{mg}$ of infused dose) as measured by liquid chromatography mass spectrometry (LC-MS)/MS. Each line represents plasma concentrations for a single patient before receiving clofarabine infusion (Pre-dose), 2 (T2), 5 (T5) and 24 (T24) hours (h) after starting of clofarabine infusion at day (d) 1 and $\mathrm{d} 5$ of the first treatment cycle. Samples from 2 patients (ns. 0708 and 0717 ) were available from two different treatment cycles. (B) A scatter plot for clofarabine plasma concentrations as measured by LC-MS/MS (in color) overlaid on the pharmacokinetic model developed by Bonate et al..$^{31}$ (in gray) for single agent clofarabine in 3 previous clinical studies (ID99383, CLO-212 and CLO-222) fitted using non-parametric LOESS fit. 
daunorubicin and high-dose cytarabine was well-tolerated in our cohort of patients. Most observed adverse events were as expected (febrile neutropenia and infections, gastrointestinal symptoms, dermatological manifestations and pain). Our data on infections are comparable to the single agent study in pediatric relapsed AML ( $67 \%$ of patients experienced $\geq$ grade 3 infections). ${ }^{13}$ The highest dose level, however, appeared not to be tolerable, again due to infectious complications. It might be that the higher anthracycline dose of $80 \mathrm{mg} / \mathrm{m}^{2}$ DNX can be tolerated in newly diagnosed patients, but this was not assessed in our study. The RP2D of clofarabine $\left(40 \mathrm{mg} / \mathrm{m}^{2}\right)$ was higher compared to the CLOUD study ( $30 \mathrm{mg} / \mathrm{m}^{2} / \mathrm{d}$ for 5 days), ${ }^{25}$ but lower than clofarabine ( $52 \mathrm{mg} / \mathrm{m}^{2} / \mathrm{d}$ for 5 days) in combination with $1 \mathrm{gram} / \mathrm{m}^{2}$ of Ara-C without anthracyclines. ${ }^{24}$

The ORR of $68 \%$ observed with this combination regimen is extremely encouraging. In addition, this response rate is higher compared than the single-agent study ${ }^{13}$ and the CLOUD study, ${ }^{25}$ and is for instance also higher than in our prior study with single-agent Mylotarg. ${ }^{33}$ Patients with early $1^{\text {st }}$ relapse $(n=15)$ responded in $93 \%$, whereas in the AML 2001/01 study only $70 \%$ (treated with FLAG-DNX) and $54 \%$ (treated with FLAG) responded, although a different definition for response was used $(\leq 20 \%$ blasts in $\mathrm{BM}$ after cycle 1). ${ }^{2}$ The number of responding patients ( 3 of 10) who were refractory to FLA-DNX chemotherapy given directly before clofarabine is also interesting, although it cannot be excluded that this was the effect of repeated chemotherapy. This was also observed in the AML 2001/01 study where 20\% of patients responded after the second FLAG course who were not in CR after the first course. ${ }^{2}$ However, we have to consider that, in our cohort, we observed a low response rate among the refractory $1^{\text {st }}$ relapse patients (CR 2 of 10, Cri 1 of 10).

Our response and survival data are in accordance with the data reported for the COG AAML0523 study. ${ }^{24}$ Of interest, $90 \%$ of the patients in this study (that combined cytarabine $1 \mathrm{~g} / \mathrm{m}^{2}$ with clofarabine $52 \mathrm{mg} / \mathrm{m}^{2}$ ) were in $1^{\text {st }}$ relapse, while the remaining $10 \%$ of patients had refractory disease. The combination of cytarabine and clofarabine in the COG study resulted in an ORR of $48 \%$ in 48 evaluable patients, and 21 of 23 responders underwent SCT. The overall survival rate at 3 years was $46 \%$ for respon- ders. ${ }^{24}$ In our study, 10 of 34 patients were still alive at last follow up, with a 2 -year pOS $32 \pm 8 \%$. This was even higher in responding patients: 2 -year pOS $48 \pm 11 \%$.

A phase III, randomized, double-blind, placebo-controlled trial was recently published in 320 adults over 55 years of age with relapsed/refractory AML, comparing cytarabine $1 \mathrm{~g} / \mathrm{m}^{2}$ plus clofarabine $40 \mathrm{mg} / \mathrm{m}^{2}$ versus cytarabine with placebo. ${ }^{27}$ This study showed significantly improved response rates and enhanced EFS in patients treated with clofarabine and cytarabine compared to placebo and cytarabine. However, no significant impact on survival was achieved, probably related to the higher incidence of mortality in the clofarabine arm. ${ }^{27}$ This is in line with the randomized study performed by Burnett et al. ${ }^{18}$ However, the recent study from Löwenberg et al. ${ }^{19}$ did show that intermediate risk AML patients in the clofarabine arm benefitted compared to cytarabine in the standard arm, including a survival benefit. Children can usually tolerate higher dosages of chemotherapy, certainly when compared to elderly patients, and the dosages used in the adult studies were very low compared to the regimen that we tested here. Better salvage regimens in relapsed pediatric AML, as summarized in various papers, ${ }^{34,35}$ including ours, have contributed to better survival rates of patients with pediatric AML in the last decade, together with improved supportive care measures. $^{3}$

Allogeneic SCT is considered the standard treatment in relapsed pediatric AML in Europe after re-induction with salvage chemotherapy. In our study, 22 patients underwent SCT following the clofarabine combination regimen. No particular toxicities (e.g. veno-occlusive disease) (data not shown) were noted during the SCT procedure, and pre-treatment with this chemotherapy combination did not preclude a successful SCT procedure.

Pharmacokinetic analysis showed no difference between data obtained with single agent clofarabine in prior studies versus clofarabine in combination in this study. Moreover, we demonstrated that cerebrospinal fluid (CSF) penetration was limited in CSF samples taken approximately $24 \mathrm{~h}$ after the last clofarabine infusion. To the best of our knowledge, this study is the first to study CSF penetration of clofarabine.

The results of this trial indicate high efficacy of the com-

Table 4. Response after cycle 1 by disease status and after prior treatment with FLA-DNX.

\begin{tabular}{|c|c|c|c|c|c|c|c|c|}
\hline & \multicolumn{2}{|c|}{ All patients } & \multicolumn{2}{|c|}{ Early $1^{\text {st }}$ relapse } & \multicolumn{2}{|c|}{ Refractory $1^{\text {st }}$ relapse } & \multicolumn{2}{|c|}{$\geq 2^{\text {nd }}$ relapse } \\
\hline & $\begin{array}{c}\text { All patients } \\
n=34\end{array}$ & $\begin{array}{c}\text { Pre-treated } \\
n=18\end{array}$ & $\begin{array}{c}\text { All patients } \\
n=15\end{array}$ & $\begin{array}{c}\text { Pre-treated } \\
n=0\end{array}$ & $\begin{array}{c}\text { All patients } \\
n=11\end{array}$ & $\begin{array}{c}\text { Pre-treated } \\
n=11\end{array}$ & $\begin{array}{c}\text { All patients } \\
n=8\end{array}$ & $\begin{array}{c}\text { Pre-treated } \\
n=7\end{array}$ \\
\hline Morphological response & 31 & 15 & 15 & & 10 & 10 & 6 & 5 \\
\hline Evaluable & $(100 \%)$ & $(100 \%)$ & $(100 \%)$ & & $(100 \%)$ & $(100 \%)$ & $(100 \%)$ & $(100 \%)$ \\
\hline CR & $5(16 \%)$ & $1(7 \%)$ & $4(27 \%)$ & & $1(10 \%)$ & $1(10 \%)$ & & \\
\hline CRi & $15(48 \%)$ & $5(33 \%)$ & $9(60 \%)$ & & $2(20 \%)$ & $2(20 \%)$ & $4(67 \%)$ & $3(60 \%)$ \\
\hline PR & $1(3 \%)$ & & $1(7 \%)$ & & & & & \\
\hline NEL & 0 & 0 & & & & & & \\
\hline SD & $6(19 \%)$ & $5(33 \%)$ & $1(7 \%)$ & & $3(30 \%)$ & $3(30 \%)$ & $2(33 \%)$ & $2(40 \%)$ \\
\hline PD & $3(10 \%)$ & $3(20 \%)$ & & & $3(30 \%)$ & $3(30 \%)$ & & \\
\hline Treatment failure & $1(3 \%)$ & $1(7 \%)$ & & & $1(10 \%)$ & $1(10 \%)$ & & \\
\hline
\end{tabular}

FLA: fludarabine, cytarabine (Ara-C); CR: complete remission; DNX: liposomal daunorubicin; n: number; CRi: morphological complete remission with incomplete blood count recovery; NEL: no evidence of leukemia; PR: partial response; SD: stable disease; PD: progressive disease. 
bination of clofarabine, liposomal daunorubicin and highdose cytarabine, while having an acceptable toxicity profile, even in heavily pre-treated patients. Of interest, clofarabine has been taken forward in front-line treatment in the AML-BFM 2012 study (EudraCT: 2013-000018-39) as an induction randomization, albeit low-dose cytarabine is used rather than high-dose.

\section{Acknowledgments}

We are grateful to all physicians and study staff who took care of the patients and contributed data for this study. We thank Dr. Simon Joel for the useful advice on the pharmacokinetic section of this study. Satianand Ramnarain was the trial-manager responsible for this study. The study was performed with financial support from Sanofi and by the KiKa-foundation grant number 26.

\section{References}

1. Gorman MF, Ji L, Ko RH, et al. Outcome for children treated for relapsed or refractory acute myelogenous leukemia (rAML): a Therapeutic Advances in Childhood Leukemia (TACL) Consortium study. Pediatr Blood Cancer. 2010;55(3):421-429.

2. Kaspers GJ, Zimmermann M, Reinhardt D, et al. Improved outcome in pediatric relapsed acute myeloid leukemia: results of a randomized trial on liposomal daunorubicin by the International BFM Study Group. J Clin Oncol. 2013;31(5):599-607.

3. Zwaan CM, Kolb EA, Reinhardt D, et al. Collaborative Efforts Driving Progress in Pediatric Acute Myeloid Leukemia. J Clin Oncol. 2015;33(27):2949-2962.

4. Milligan DW, Wheatley K, Littlewood T, Craig JI, Burnett AK, Group NHOCS. Fludarabine and cytosine are less effective than standard ADE chemotherapy in highrisk acute myeloid leukemia, and addition of G-CSF and ATRA are not beneficial: results of the MRC AML-HR randomized trial. Blood. 2006;107(12):4614-4622

5. Ehlers S, Herbst C, Zimmermann M, et al. Granulocyte colony-stimulating factor (GCSF) treatment of childhood acute myeloid leukemias that overexpress the differentiation-defective G-CSF receptor isoform IV is associated with a higher incidence of relapse. J Clin Oncol. 2010;28(15):25912597.

6. Sander A, Zimmermann M, Dworzak M, et al. Consequent and intensified relapse therapy improved survival in pediatric AML: results of relapse treatment in 379 patients of three consecutive AML-BFM trials. Leukemia. 2010;24(8):1422-1428.

7. Kremer LC, van der Pal HJ, Offringa M, van Dalen EC, Voute PA. Frequency and risk factors of subclinical cardiotoxicity after anthracycline therapy in children: a systematic review. Ann Oncol. 2002;13(6):819829.

8. Lipshultz SE, Colan SD, Gelber RD, PerezAtayde AR, Sallan SE, Sanders SP. Late cardiac effects of doxorubicin therapy for acute lymphoblastic leukemia in childhood. N Engl J Med. 1991;324(12):808-815.

9. Pui CH, Jeha S, Kirkpatrick P. Clofarabine. Nat Rev Drug Discov. 2005;4(5):369-370.

10. Bonate PL, Arthaud L, Cantrell WR Jr, Stephenson K, Secrist JA 3rd, Weitman S. Discovery and development of clofarabine: a nucleoside analogue for treating cancer. Nat Rev Drug Discov. 2006;5(10):855-863.

11. Faderl S, Gandhi V, O'Brien S, et al. Results of a phase 1-2 study of clofarabine in combination with cytarabine (ara-C) in relapsed and refractory acute leukemias. Blood. 2005;105(3):940-947.

12. Jeha S, Gandhi V, Chan KW, et al.
Clofarabine, a novel nucleoside analog, is active in pediatric patients with advanced leukemia. Blood. 2004;103(3):784-789.

13. Jeha S, Razzouk B, Rytting M, et al. Phase II study of clofarabine in pediatric patients with refractory or relapsed acute myeloid leukemia. J Clin Oncol. 2009;27(26):43924397.

14. Tiley S, Claxton D. Clofarabine in the treatment of acute myeloid leukemia in older adults. Ther Adv Hematol. 2013;4(1):5-13.

15. Kantariian HM, Erba HP, Claxton D, et al. Phase II study of clofarabine monotherapy in previously untreated older adults with acute myeloid leukemia and unfavorable prognostic factors. J Clin Oncol. 2010; 28(4):549-555.

16. Burnett AK, Russell NH, Kell J, et al. European development of clofarabine as treatment for older patients with acute myeloid leukemia considered unsuitable for intensive chemotherapy. J Clin Oncol. 2010;28(14):2389-2395.

17. Burnett AK, Russell NH, Hunter AE, et al. Clofarabine doubles the response rate in older patients with acute myeloid leukemia but does not improve survival. Blood. 2013;122(8):1384-1394.

18. Burnett AK, Russell NH, Hills RK, et al. A comparison of clofarabine with ara-C, each in combination with daunorubicin as induction treatment in older patients with acute myeloid leukaemia. Leukemia. 2017; 31(2):310-317.

19. Lowenberg B, Pabst T, Maertens J, et al. Therapeutic value of clofarabine in younger and middle-aged (18-65 years) adults with newly diagnosed AML. Blood. 2017;129(12):1636-1645.

20. Abd Elmoneim A, Gore L, Ricklis RM, et al. Phase I dose-escalation trial of clofarabine followed by escalating doses of fractionated cyclophosphamide in children with relapsed or refractory acute leukemias. Pediatr Blood Cancer. 2012;59(7):12521258.

21. Hijiya N, Gaynon P, Barry E, et al. A multicenter phase I study of clofarabine, etoposide and cyclophosphamide in combination in pediatric patients with refractory or relapsed acute leukemia. Leukemia. 2009; 23(12):2259-2264.

22. Hijiya $\mathrm{N}$, Thomson $\mathrm{B}$, Isakoff $\mathrm{MS}$, et al. Phase 2 trial of clofarabine in combination with etoposide and cyclophosphamide in pediatric patients with refractory or relapsed acute lymphoblastic leukemia. Blood. 2011;118(23):6043-6049.

23. Shukla N, Kobos R, Renaud T, Steinherz LJ, Steinherz PG. Phase II trial of clofarabine with topotecan, vinorelbine, and thiotepa in pediatric patients with relapsed or refractory acute leukemia. Pediatr Blood Cancer. 2014;61(3):431-435.

24. Cooper TM, Alonzo TA, Gerbing RB, et al.
AAML0523: a report from the Children's Oncology Group on the efficacy of clofarabine in combination with cytarabine in pediatric patients with recurrent acute myeloid leukemia. Cancer. 2014; 120(16):2482-2489.

25. Kearns P, Graham NJ, Cummins B, et al Phase I study of clofarabine and liposomal daunorubicin in childhood acute myeloid leukemia [abstract]. J Clin Oncol. 2011; 29(Suppl 15):Abstract 9521

26. Faderl S, Verstovsek S, Cortes J, et al. Clofarabine and cytarabine combination as induction therapy for acute myeloid leukemia (AML) in patients 50 years of age or older. Blood. 2006;108(1):45-51.

27. Faderl S, Wetzler M, Rizzieri D, et al. Clofarabine plus cytarabine compared with cytarabine alone in older patients with relapsed or refractory acute myelogenous leukemia: results from the CLASSIC I Trial. J Clin Oncol. 2012;30(20):2492-2499.

28. Creutzig U, Zimmermann M, Bourquin JP, et al. Randomized trial comparing liposomal daunorubicin with idarubicin as induction for pediatric acute myeloid leukemia: results from Study AML-BFM 2004. Blood. 2013;122(1):37-43.

29. Creutzig U, Diekamp S, Zimmerman M Reinhardt D. Longitudinal evaluation of early and late anthracycline carciotoxicity in children with AML. Pediatr Blood Cancer. 2007;48(7):651-662.

30. Berg SL, Bonate PL, Nuchtern JG, et al. Plasma and cerebrospinal fluid pharmacokinetics of clofarabine in nonhuman primates. Clin Cancer Res. 2005;11(16):59815983.

31. Bonate PL, Craig A, Gaynon P, et al. Population pharmacokinetics of clofarabine, a second-generation nucleoside ana$\log$, in pediatric patients with acute leukemia. J Clin Pharmacol. 2004:44(11):1309-1322.

32. Joel S, Ghazaly E, Smith H, Kearns P, Saha $\mathrm{V}$. The plasma and intracellular pharmacokinetics of clofarabine in pediatric leukemia patients. Cancer Res. 2007;67(Suppl 9):Abstract 1566

33. Zwaan CM, Reinhardt D, Zimmerman M, et al. Salvage treatment for children with refractory first or second relapse of acute myeloid leukaemia with gemtuzumab ozogamicin: results of a phase II study. $\mathrm{Br}$ J Haematol. 2010;148(5):768-776.

34. Kaspers GJ. How I treat paediatric relapsed acute myeloid leukaemia. Br J Haematol. 2014;166(5):636-645.

35. Creutzig U, Zimmermann M, Dworzak $\mathrm{MN}$, et al. The prognostic significance of early treatment response in pediatric relapsed acute myeloid leukemia: results of the international study Relapsed AML 2001/01. Haematologica. 2014;99(9):14721478. 